\title{
Field decomposition of transgenic Bt maize residue and the impact on non-target soil invertebrates
}

\author{
C. Zwahlen • A. Hilbeck $\cdot$ W. Nentwig
}

Received: 18 May 2007 / Accepted: 22 August 2007 /Published online: 21 September 2007

(C) Springer Science + Business Media B.V. 2007

\begin{abstract}
Genetically modified Bacillus thuringiensis Berliner (Bt) maize (Zea mays L.) expressing Cry toxins against various target pests is now grown on more than 16 million hectares worldwide, but its potential effects on the soil ecosystem need to be further investigated. In an 8-month field study, we investigated the effects of $\mathrm{Bt}$ maize expressing the Cry1 $\mathrm{Ab}$ protein on both the soil community and maize residue decomposition. We used litterbags with three different mesh sizes $(20,125$, and 5,000 $\mu \mathrm{m})$ to investigate potential effects of different soil organism groups on the decomposition processes. Litterbags were incorporated into the soil in fall into a field that had previously been planted with non-Bt maize and
\end{abstract}

Responsible Editor: Per Ambus

C. Zwahlen $(\bowtie)$

Institute of Biology, University of Neuchâtel,

Rue Emile-Argand 11, Case postale 158,

CH-2009 Neuchâtel, Switzerland

e-mail: claudia.zwahlen@gmx.net

C. Zwahlen · W. Nentwig

Zoological Institute, University of Bern,

Baltzerstrasse 6,

CH-3012 Bern, Switzerland

A. Hilbeck

Institute of Integrative Biology, ETH Zurich,

Universitätsstrasse 16 ,

CH-8092 Zurich, Switzerland subsamples were removed monthly. The dry weight of the remaining residue was measured for all bags. $\mathrm{Bt}$ and non-Bt maize decomposed similarly in large mesh bags, which allowed the whole soil organism community to enter and interact with each other. In contrast, Bt maize decomposed significantly faster than non-Bt maize at some sample dates in winter in bags with small and medium mesh sizes. At the end of the experiment in late spring, however, there was no significant difference in the amount of maize plant residues remaining for any of these three mesh sizes. Additionally, soil organisms from bags with the largest mesh size were identified. The most frequent taxa extracted were collembolans (Isotomidae, Tullbergiidae, Entomobryidae), mites (Gamasina, Oribatida), and annelids (Enchytraeidae). Three of these taxa were extracted in higher numbers from non-Bt than Bt residue (Tullbergiidae, Gamasina, Enchytraeidae), while there was no difference in the number of individuals extracted for the remaining three taxa. Our results do not show major changes in the decomposition of $\mathrm{Bt}$ maize residue and in the composition of the soil organism community. However, further studies are needed that assess the impact of the continuous release of Cry1 $\mathrm{Ab}$ via root exudates and plant biomass on the soil ecosystem.

Keywords Transgenic Bt corn · Decomposition process $\cdot$ Risk assessment $\cdot$ Collembola $\cdot$ Acarina . Annelida 


\section{Introduction}

Transgenic Bacillus thuringiensis (Bt) maize plants expressing toxins against lepidopteran (Cry1 Ab protein) and/or coleopteran pests (Cry3Bb1) contain one or two genes that originate from gram-positive Bacillus thuringiensis bacteria strains. Although $B$. thuringiensis strains have been detected in soils from all over the world (DeLucca et al. 1981; Ohba and Aizawa 1986; Martin and Travers 1989), their ecological role is still unclear. Smith and Couché (1991) hypothesized that the bacterium is a natural component of the phylloplane microflora that has evolved in a symbiotic or mutualistic association with plants to provide protection against herbivores. Addison (1993) suggested that B. thuringiensis protein production might have evolved as a defense against invertebrates feeding on bacteria or potential microbial competitors in soil and he presented evidence that several groups of taxa with representatives in the soil fauna, such as earthworms (Smirnoff and Heimpel 1961; Atlavinyté et al.1982), nematodes (Bottjer et al. 1985; Meadows et al. 1990) and mites (Oatman 1965; Chapman and Hoy 1991), are indeed susceptible to $B$. thuringiensis. Many of these studies focused on organisms of economic importance. Since most studies were done with Bt strains or Bt sprays that produce a mixture of different toxins, it is unclear whether the toxicity of $B$. thuringiensis found in these studies is mostly due to a specific toxin or a combination of them. It is therefore necessary to specifically investigate the impact of transgenic plants expressing one or two toxins on non-target soil organisms and the soil ecosystem.

Directional changes that take place in the soil ecosystem often cannot be directly observed and it may take years or decades before they become evident. In the soil ecosystem, the detection of ecological consequences of Bt maize cultivation is difficult because sampling is time consuming and there is high variability among samples. However, it is now known that $\mathrm{Cry} 1 \mathrm{Ab}$ protein from transgenic $\mathrm{Bt}$ maize can enter the soil via plant residues after harvest, roots exudates, and deposition of dead plant material, such as leaves and pollen. During plant growth $\mathrm{Cry} 1 \mathrm{Ab}$ is released by roots and persists at least until the occurrence of the first frost (Saxena et al. 1999; Saxena and Stotzky 2000; Saxena and Stotzky 2001b). The main source of Bt proteins entering the soil is most likely via plant residues, as 2 to 6 tons of residue per hectare are left on the field after harvest (Zscheischler et al. 1984), and the $\mathrm{Cry} 1 \mathrm{Ab}$ can persist in the plant matrix for at least 2 years after sowing (Zwahlen et al. 2003a b; Hasselmann et al. unpublished data). Cry1 Ab proteins have also been found in leachates from soils that were amended with Bt maize biomass up to 3 years earlier (Saxena et al. 2002; Saxena and Stotzky 2003). These results suggest that soil organisms associated with the decomposer food web are likely to be exposed to $\mathrm{Cry} 1 \mathrm{Ab}$ from transgenic maize. Although it is still unknown for many soil organism groups whether they are exposed to Bt from transgenic maize, it has been shown that adult carabid beetles in fields containing 7 to 10 month old $\mathrm{Bt}$ maize residues had taken up the Cry1Ab (Zwahlen and Andow 2005; Hasselmann et al. unpublished data). Dissemination of Cry $1 \mathrm{Ab}$ in the soil food web is therefore likely. If indeed such exposure of soil invertebrates occurs, direct effects of $\mathrm{Bt}$ proteins on them cannot be excluded.

Because soil invertebrates have an integral role in maintaining and shaping microbial activity and community structure, contribute significantly to decomposition and nutrient cycling, and are important mediators of food web stability (Moore et al. 1988), it is important to investigate the impact of Bt maize on them. While several studies did not find any adverse effects of Cry1 Ab Bt maize on soil organisms such as bacteria, protozoa, nematodes, collembolans, woodlice, and earthworms (Sims and Martin 1997; Escher et al. 2000; Saxena and Stotzky 2001a; Clark and Coats 2006; Clark et al. 2006; Heckmann et al. 2006), other studies have shown adverse effects of Bt maize on some life history traits of woodlice (Wandeler et al. 2002), earthworms (Zwahlen et al. 2003b; Vercesi et al. 2006), carabid beetles (Meissle et al. 2005) and nematodes (Griffiths et al. 2005). It often remains unclear whether such effects on non-target organisms are due to the toxicity of the Cry $1 \mathrm{Ab}$, pleiotropic effects resulting from the genetic transformation (e.g., Donegan et al. 1995; Saxena and Stotzky 2001c, Turlings et al. 2005), prey-mediated effects, or some combination of these. Such effects may influence decomposition processes and hence nutrient cycling (Fierer et al. 2005).

Laboratory and greenhouse studies on the decomposition of CrylAb $\mathrm{Bt}$ maize have found that $\mathrm{Bt}$ maize either decomposes at a similar rate or more 
slowly than non-Bt maize (Hopkins and Gregorich 2003; Castaldini et al. 2005; Flores et al. 2005; Raubuch et al. 2007). Slower rates of residue decomposition can result in nutrient limitations for primary producers and decreased nutrient cycling. The accumulation of plant residues in the soil might cause a longer persistence and subsequent accumulation of Cryl $\mathrm{Ab}$ protein, thereby enhancing the probability of exposure for non-target soil organisms (Saxena and Stotzky 2001c). On the other hand, slow residue decomposition might also lead to a higher accumulation of organic material in the soil, which can improve soil structure and reduce erosion (Gisi et al. 1997; James et al. 1998).

Studies on the decomposition of Bt maize should include larger soil invertebrates, such as earthworms, millipedes, and isopods, since these larger organisms are known to process large amounts of dead plant material, thereby greatly impacting nutrient cycling in many ecosystems. In our 240-day field study, we allowed larger invertebrates to access the maize residues in some treatments. We examined if Cry1 Ab $\mathrm{Bt}$ maize residue affects the soil invertebrate community and residue decomposition. The near isogenic non-Bt maize hybrid was used as a comparison. We used litterbags with three different mesh sizes to physically exclude soil organisms of increasing size ranging from (1) microorganisms, meso- and macrofauna; (2) microorganisms and mesofauna; to (3) mainly microorganisms. This technique allowed us to determine the effect of Bt maize on the soil organism community as a whole, on microorganisms and the mesofauna, and on microorganisms alone. Specifically, our hypotheses were: (H1) Fewer soil organisms will be extracted from litterbags containing $\mathrm{Cry} 1 \mathrm{Ab} \mathrm{Bt}$ maize residue than containing non-Bt maize residue, and (H2) Cry1 Ab Bt maize decomposes at a slower rate than non-Bt maize, thus indicating direct or indirect effects of Bt maize on soil invertebrates that play an important role in the decomposition process.

\section{Materials and methods}

Plant residues

Two maize (Zea mays L.) hybrids were used in the experiment. One was genetically modified maize from Syngenta (N4640Bt, transformation event Bt11; referred to as ' $\mathrm{Bt}$ ') containing a truncated, synthetic version of a gene from Bacillus thuringiensis subsp. kurstaki Berliner coding for the expression of the insecticidal $\delta$-endotoxin CrylAb. The control maize hybrid was the near isogenic line of the previously described one, which was not genetically modified (N4640; referred to as 'non-Bt'). The plants were cultivated in plastic pots in a plant-growth chamber at an average temperature of $23.3^{\circ} \mathrm{C}\left(20^{\circ} \mathrm{C}\right.$ for $8 \mathrm{~h}$ in the dark and $25^{\circ} \mathrm{C}$ for $16 \mathrm{~h}$ in the light). Live leaves of plants in their reproductive stage, shortly before and after tasseling, were cut into approximately $8 \mathrm{~cm}$ pieces and plant material was dried at $40^{\circ} \mathrm{C}$ for $72 \mathrm{~h}$ for residue production. Using leaves instead of other tissues that are left on maize fields after harvest and using them in their reproductive stage rather than during senescence ensured that decomposer soil organisms were exposed to high levels of Cry1 Ab. Leaves of maize plants from transformation event Bt11 are known to express higher Cry1 Ab concentrations than any to other tissues that are left in the field after harvest (US Environmental Protection Agency 1997). Cry1Ab concentration in leaves during their reproductive stage was high (15.4 \pm $4.3 \mu \mathrm{g} / \mathrm{g}$ dry weight for plants used in this experiment, Zwahlen et al. 2003a) and is likely to be higher than in senescent leaves (Fearing et al. 1997). This represents a conservative approach in the risk assessment of transgenic plants (Andow and Zwahlen 2006): If our tests indicate that there might be significant risks, then these risks are likely to be smaller than indicated and further tests will be necessary. In contrast, if they indicate that the risks might be insignificant, it is unlikely that there are significant risks when Cry1 $\mathrm{Ab}$ concentrations are lower.

\section{Litterbags}

Three different types of litterbags were used varying in mesh size, which is a widely used technique for physically excluding broad categories of soil organisms (e.g., House and Stinner 1987; Bradford et al. 2002). Different taxa of soil organisms are frequently categorized as microorganisms, meso- and macrofauna (Scheffer and Schachtschabel 1989; Zettel 1999), although smaller (e.g., immature stages) or larger individuals of a taxon can occasionally also belong to the respective neighboring category. According to Scheffer and Schachtschabel (1989) and Zettel (1999), microorganisms have a size of 0.002 to $0.2 \mathrm{~m}$ and belong to the microflora (bacteria, actinomycetes fungi, algae) or microfauna (Protozoa, 
Rotatoria, Tardigrada). The mesofauna includes mainly Nematoda, Acari and Apterygota (mainly Collembola) with a size of 0.2 to $2 \mathrm{~mm}$, whereas the macrofauna consists of taxa with a size of approximately 1 to $20 \mathrm{~mm}$, such as Enchytraeidae, Lumbricidae, Mollusca, Araneae, Isopoda, Myriapoda, Coleoptera and Diptera.

Litterbags with the largest mesh size $(5,000 \mu \mathrm{m}$, referred to as 'large mesh'), allowed the whole invertebrate soil fauna (microorganisms, meso- and macrofauna) to enter the litterbags. The medium-sized litterbags (125 $\mu \mathrm{m}$, referred to as 'medium mesh'), mainly excluded the macrofauna, and litterbags with the smallest mesh size $(20 \mu \mathrm{m}$, referred to as 'small mesh'), mainly allowed microorganisms and the very small microfauna to enter. Large and medium mesh size bags had a size of $20 \times 20 \mathrm{~cm}^{2}$ and were filled with $2 \mathrm{~g}$ of maize residues $(\approx 25-35$ leaf pieces). Small mesh size bags had a size of $10 \times 10 \mathrm{~cm}^{2}$ and were filled with $0.5 \mathrm{~g}$ of maize residues $(\approx 8-10$ leaf pieces). Mesh bags of all sizes were filled with either Bt or non-Bt maize, thus, resulting in three mesh bag pairs and a total of six treatments. Large mesh bags consisted of synthetic curtain cloth and all sides were sewn whereas medium and small mesh bags were made of nylon and seams were sealed with universal glue.

\section{Experimental design}

The experiment was carried out in a non-transgenic maize field near Bern, Switzerland, immediately following the harvest of silage maize and ploughing and sowing of winter barley in mid-October 1999. The soil in this field was a Cambisol loam (50\% sand, $33 \%$ silt, $17 \%$ clay, $\mathrm{pH} 5.7$ ).

The litterbags were buried vertically at a depth of 0 to $20 \mathrm{~cm}$ for the large and medium mesh size bags and 0 to $10 \mathrm{~cm}$ for the small mesh size bags at a total of 60 locations. In each location, one litterbag per treatment was buried (i.e., a total of six bags). The bags were assigned randomly in a hexagonal arrangement, with each mesh size pair (i.e., Bt and non-Bt of the same mesh size) having a randomly assigned $\mathrm{Bt}$ and non-Bt treatment located next to each other (i.e., mesh bag pairs were randomly located besides each other and Bt and non-Bt treatment of each mesh size were randomly located besides each other; Fig. 1). Ten such sample locations were evenly spread along one row of $9 \mathrm{~m}$ in length; thus, the distance between

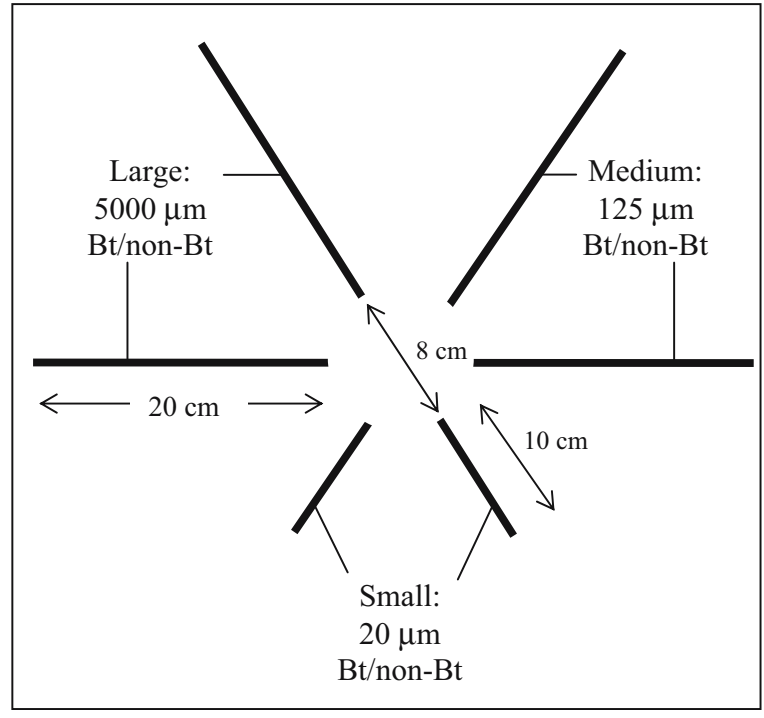

Fig. 1 Example of hexagonal arrangement within one location. At each of the 60 field locations, this hexagonal arrangement of the six litterbags was randomly assigned, with each mesh size pair (i.e., Bt and non-Bt of the same mesh size) having a randomly assigned $\mathrm{Bt}$ and non-Bt treatment located next to each other. Given are mesh size, hybrid and side length of litterbags

two neighboring locations was $1 \mathrm{~m}$. This was repeated six times, resulting in six field rows within an area of $9 \times 5 \mathrm{~m}^{2}$ and a total of 360 litterbags (i.e., 2 hybrids $\times 3$ mesh types $\times 10$ locations per row $\times 6$ rows).

In monthly intervals from mid-November to midJune, the litterbags from seven to eight locations were completely randomly sampled across all 60 locations and brought back to the laboratory. Litterbags from one location per sample date were used for the quantification of the Cryl Ab concentration in the remaining leaves using enzyme-linked immunosorbent assay (ELISA) and for the determination of the insecticidal activity of the Cry1 Ab. The results of this part of the study are published elsewhere (Zwahlen et al. 2003a) and will only briefly be discussed in this paper. The remaining six to seven litterbags were used for the analyses as described below.

\section{Soil organisms (H1)}

Only soil organisms from litterbags with the largest mesh size were recorded. Litterbags were put into a MacFadyen-Extractor (MacFadyen 1961, 1962) for 7 days to extract the soil organisms. They were caught in vials filled with isopropanol. After the extraction procedure, the isopropanol in the vials was exchanged 
with $70 \%(v / v)$ ethanol. The animals were identified on order, suborder, cohors, or family level after Zettel (1999). The MacFadyen-Extractor allows efficient and thorough sampling of some microarthropod groups, such as Collembola and some groups of Acari (MacFadyen 1961), whereas for other taxa, such as Nematoda and Enchytraeidae, other extraction methods would have been more efficient. Although the number of soil organisms extracted does not always represent population abundance in litterbags, this method allowed us to compare the numbers of particular soil invertebrates from Bt and non-Bt maize residues.

Data analysis To test the hypothesis (H1) that fewer individuals are collected from Cry $1 \mathrm{Ab} \mathrm{Bt}$ maize than non-Bt maize residue, numbers of individuals from the same taxon were compared using the Generalized Linear Mixed model (GLMM) with Poisson distribution using PROC GLIMMIX (SAS 9.1., SAS Institute Inc. 2004, 2006). The model accounted for overdispersion with a quasi-likelihood model, which estimates the dispersion parameter from the data rather than restrict it to the value defined by a Poisson distribution, using the term random_residual in SAS (SAS 9.1., SAS Institute Inc. 2004, 2006). This corresponds to a negative binomial distribution. Date, hybrid, and location were independent variables, whereas date and hybrid were fixed factors and location nested within date a random factor. The number of individuals extracted was the dependent variable. Differences were analyzed using LSMEANS with Bonferroni adjustment for the $p$-values (SAS 9.1.). To see whether there were differences in the number of individuals extracted of each taxon at specific dates of the experiment, data for each date were then analyzed separately using the same GLMM procedure as described above. Analyses were only carried out with soil organism groups that had more than 200 individuals per taxon and maize hybrid, which were the collembolan families Isotomidae, Tullbergiidae and Entomobryidae, the mites Gamasina and Oribatida, and the annelids of the family Enchytraeidae.

Maize residue decomposition (H2)

Dry weight Residue from large and medium mesh bags were placed in a plastic container and thoroughly washed with water to remove soil particles, root and other non-maize particles. A fine mesh sieve and forceps were used during the procedure to prevent the loss of plant material. This washing process was not necessary for maize residue from $20 \mu \mathrm{m}$ mesh bags since the small mesh size prevented residue in the bags to be contaminated with such particles. All samples were dried at $40^{\circ} \mathrm{C}$ for 7 days and the dry weight was recorded. The proportion of residue remaining was then calculated as the difference in dry weight between the initial dry weight of the sample and the recorded dry weight.

Data analysis To test the hypothesis (H2) that Cry1Ab Bt maize decomposes at a slower rate than non-Bt maize, the proportions of residue remaining were compared using ANOVA (PROC MIXED, SAS 9.1.). Date, hybrid, mesh size, date*mesh size, date*hybrid, mesh*hybrid interactions, and location were independent variables, whereas date, hybrid, and mesh size were fixed factors and location nested within date a random factor. The dry weight was the dependent variable. Differences were analyzed using LSMEANS with Tukey-Kramer adjustments for the $p$-values (SAS 9.1.). To analyze whether there were differences in the decomposition among litterbags with the same mesh size, data for each mesh size type were then analyzed separately using the same ANOVA procedure as described above. The same analysis was also carried out to find out whether there were differences in the decomposition of $\mathrm{Bt}$ and non$\mathrm{Bt}$ maize residue at specific dates in litterbags with the same mesh size by analyzing the data separately for each date.

\section{Results}

Soil organisms

In total, 6,396 and 7,337 individuals belonging to 32 taxa and 36 taxa were extracted from Bt and non-Bt maize litter, respectively (Table 1). Although some taxa were only found in one of the treatments, the number of individuals belonging to these taxa was low with one to five individuals per taxon. In both treatments, more than $50 \%$ of all individuals extracted were collembolans and more than $30 \%$ of all 
Table 1 Total number of individuals of taxonomic units extracted from large litterbags filled either with $\mathrm{Bt}$ or non-Bt maize during the whole experiment

\begin{tabular}{|c|c|c|}
\hline \multirow[b]{2}{*}{ Taxa } & \multicolumn{2}{|c|}{ Individuals (no.) } \\
\hline & $\mathrm{Bt}$ & Non-Bt \\
\hline \multicolumn{3}{|l|}{ Arachnida } \\
\hline Araneae & 9 & 6 \\
\hline \multicolumn{3}{|l|}{ Acarina } \\
\hline \multicolumn{3}{|l|}{ Mesostigmata } \\
\hline Gamasina & 1,364 & 1,634 \\
\hline Uropodina & 53 & 62 \\
\hline Prostigmata & 186 & 182 \\
\hline Astigmata & 4 & 6 \\
\hline Cryptostigmata (Oribatida) & 464 & 436 \\
\hline Nematoda & 71 & 104 \\
\hline \multicolumn{3}{|l|}{ Clitellata } \\
\hline Lumbricidae & 14 & 15 \\
\hline Enchytraeidae & 706 & 973 \\
\hline \multicolumn{3}{|l|}{ Crustacea } \\
\hline Isopoda & 0 & 0 \\
\hline \multicolumn{3}{|l|}{ Myriapoda } \\
\hline Chilopoda & 0 & 1 \\
\hline \multicolumn{3}{|l|}{ Diplopoda } \\
\hline Polydesmidae & 13 & 12 \\
\hline Chordeumatidae & 2 & 2 \\
\hline Julidae & 0 & 1 \\
\hline Pauropoda & 20 & 32 \\
\hline Symphyla & 1 & 1 \\
\hline \multicolumn{3}{|l|}{ Hexapoda } \\
\hline \multicolumn{3}{|l|}{ Collembola } \\
\hline Hypogasturidae & 49 & 55 \\
\hline Neanuridae & 1 & 0 \\
\hline Tullbergiidae & 684 & 994 \\
\hline Onychiuridae & 10 & 21 \\
\hline Isotomidae & 2,230 & 2,319 \\
\hline Entomobryidae & 273 & 244 \\
\hline Neelidae & 80 & 82 \\
\hline Sminthuridae & 4 & 3 \\
\hline Sminthurididae & 20 & 26 \\
\hline Psocoptera & 38 & 34 \\
\hline \multicolumn{3}{|l|}{ Diptera - Larvae } \\
\hline Chironomidae & 8 & 18 \\
\hline Cecidomyiidae & 16 & 15 \\
\hline Mycetophilidae & 0 & 5 \\
\hline Sciaridae & 0 & 2 \\
\hline Scatopsidae & 1 & 0 \\
\hline Dolichopodidae & 18 & 12 \\
\hline Rhagionidae & 0 & 1 \\
\hline Anthiomyiidae & 1 & 0 \\
\hline div. Cyclorrhapha & 0 & 3 \\
\hline Diptera - Pupae & 2 & 2 \\
\hline Diptera - Imagines & 3 & 3 \\
\hline
\end{tabular}

Table 1 (continued)

\begin{tabular}{lll}
\hline & \multicolumn{2}{l}{ Individuals (no.) } \\
\cline { 2 - 3 } Taxa & $\mathrm{Bt}$ & Non-Bt \\
\hline Coleoptera - Larvae/Imagines & & \\
Staphylinidae & 19 & 9 \\
Carabidae & 1 & 2 \\
Lepidoptera - Larvae & 0 & 1 \\
\hline
\end{tabular}

individuals were mites. The majority of the individuals extracted, approximately one third (Bt: $34.9 \%$; non-Bt: $31.6 \%$ ) of all individuals, belonged to the collembolan family Isotomidae (Table 1). The second most frequently extracted taxon was gamasid mites accounting for 21.3 and $22.3 \%$ of all individuals extracted in the Bt and non-Bt treatment, respectively. The number of Enchytraeidae (Annelida) and Tullbergiidae (Collembola) extracted was between 10.7 and $13.5 \%$ of all individuals. Further taxa accounting for more than $1 \%$ of all individuals extracted (i.e., more than 63 and 73 individuals in the $\mathrm{Bt}$ and non-Bt treatment, respectively), were the mites Oribatida and Prostigmata, the collembolan families Entomobryidae and Neelidae (Collembola), and Nematoda. Some of these groups, such as nematodes, are likely to have been largely underestimated due to the extraction method used. It has been found that nematodes often account for more than a third of the biomass of the smaller invertebrate fauna (de Ruiter et al. 1995), which include mites, Collembola, and Enchytraeids.

Isotomidae There was a significant overall date effect but no hybrid effect (Table 2). The date effect was probably due to a tendency towards a lower number of isotomids during fall and winter than during spring (Fig. 2a). When sample dates were analyzed separately for hybrid effects, we did not observe any statistical differences between $\mathrm{Bt}$ and non-Bt.

Tullbergiidae There was no significant date effect, but there was a significant hybrid effect (Table 2) with less individuals being found in $\mathrm{Bt}$ than non-Bt litterbags (LSMEANS: Bonferroni-adjusted $P=$ $0.0033)$. The same hybrid effect was found in December, when significantly fewer individuals were found in the Bt than the non-Bt treatment $(d f=1,6 ; F=$ 8.01; $P=0.0299$; Fig. 2b). This was not the case for any of the other dates. 
Table 2 Generalized linear mixed model (GLMM) results of the overall effects on the number of Isotomidae (Collembola), Tullbergiidae (Collembola), Entomobryidae (Collembola), Gamasina (Acarina), Oribatida (Acarina), and Enchytraeidae

\begin{tabular}{llll}
\hline Source & $d f$ & $F$ & $P$ \\
\hline Isotomidae & & & \\
$\quad$ Date & $7 ; 43$ & 2.28 & 0.0453 \\
$\quad$ Hybrid & $1 ; 50$ & 0.13 & 0.7229 \\
Tullbergiidae & & & \\
$\quad$ Date & $7 ; 43$ & 1.26 & 0.2912 \\
$\quad$ Hybrid & $1 ; 50$ & 9.52 & 0.0033 \\
Entomobryidae & & & \\
$\quad$ Date & $7 ; 43$ & 4.17 & 0.0014 \\
$\quad$ Hybrid & $1 ; 50$ & 0.67 & 0.4176 \\
Gamasina & & & \\
$\quad \begin{array}{l}\text { Date } \\
\text { Hybrid }\end{array}$ & $7 ; 43$ & 19.08 & $<0.0001$ \\
Oribatida & $1 ; 50$ & 4.60 & 0.0368 \\
$\quad$ Date & $7 ; 43$ & 19.14 & $<0.0001$ \\
$\quad$ Hybrid & $1 ; 50$ & 0.35 & 0.5540 \\
Enchytraeidae & & & \\
$\quad$ Date & $7 ; 43$ & 1.80 & 0.1115 \\
Hybrid & $1 ; 50$ & 9.84 & 0.0029 \\
\hline
\end{tabular}

Entomobryidae There was a significant date effect but no significant overall hybrid effect (Table 2). No significant differences between Bt and non-Bt treatment were found for single dates except for January, when significantly more individuals were extracted from Bt than non-Bt litterbags $(d f=1,6 ; F=6.38 ; P=$ 0.0450; Fig. 2c).

Gamasina There was a significant date effect, which was probably due to a higher number of mites found during winter than spring (Table 2, Fig. 2f). The majority of Gamasina are predators feeding on nematodes, collembolans, mites, and insect larvae (Koehler 1999), which might explain the increase of other taxonomic groups investigated in spring, such as Isotomidae and Oribatida. We also found a significant hybrid effect (Table 2) with more individuals extracted from non-Bt than $\mathrm{Bt}$ maize residue (LSMEANS: Bonferroni-adjusted $P=0.0368$ ). However, no significant differences between $\mathrm{Bt}$ and non-Bt treatment were observed for individual sample dates (Fig. 2d).

Oribatida There was a significant date effect, but no hybrid effect (Table 2). The mean number of oribatid mites was low during fall and winter, but increased continuously in both treatments during spring until reaching a maximum at the end of the experiment
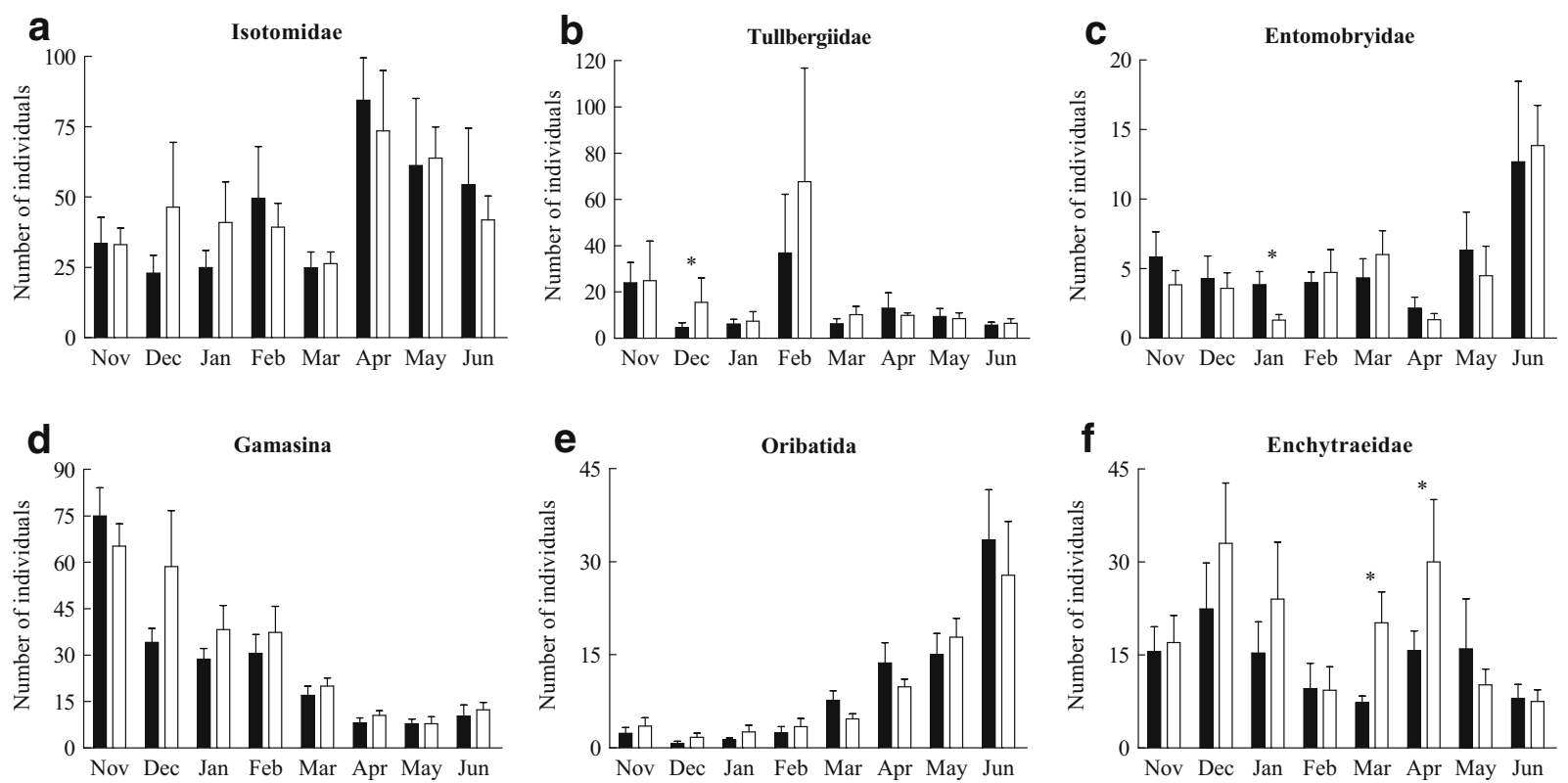

Fig. 2 a-f Mean $( \pm S E)$ number of individuals of the six most frequent taxa in large mesh litterbags $(5,000 \mu \mathrm{m})$ filled with either $\mathrm{Bt}$ or non-Bt maize residue (black bars $\mathrm{Bt}$; white bars non-Bt). Taxonomic units are a Isotomidae (Collembola), b
Tullbergiidae (Collembola), c Entomobryidae (Collembola), d Gamasina (Acarina), e Oribatida (Acarina), and f Enchytraeidae (Oligochaeta). Columns with asterisks represent statistically significant differences at $P=0.05$ 
(Fig. 2e). Our analysis of the number of oribatid mites at single dates showed no statistical differences.

Enchytraeidae There was no significant date effect, but a significant hybrid effect (Table 2) with fewer individuals in the $\mathrm{Bt}$ than the non-Bt maize residue (LSMEANS: Bonferroni-adjusted $P=0.00029$ ). The same hybrid effect with fewer individuals in the $\mathrm{Bt}$ than non-Bt treatment was also found in March and April (March: $d f=1,5 ; F=9.13 ; P=0.0294$; April: $d f=$ 1,$5 ; F=6.74 ; P=0.0485$; Fig. 2f).

\section{Decomposition of maize residue}

The analysis of all mesh sizes together showed significant date, mesh, hybrid, and date*mesh interaction effects, but no date*hybrid and mesh*hybrid effects (Table 3). The hybrid effect was due to a significantly lower proportion of $\mathrm{Bt}$ maize residue remaining than non-Bt maize residue (LSMEANS: Tukey-Kramer-adjusted $P<0.0001)$. Further analyses of separate mesh sizes revealed this effect was mainly due to the significantly faster decomposition of $\mathrm{Bt}$ than non-Bt maize in small and medium mesh bags,

Table 3 Generalized linear mixed model (GLMM) results of the overall effects on residue decomposition (measured as proportion residue remaining) for all mesh sizes together and for each mesh size separately

\begin{tabular}{llll}
\hline Source & $d f$ & $F$ & $P$ \\
\hline All mesh sizes & & & \\
Date & $7 ; 44$ & 166.85 & $<0.0001$ \\
Mesh & $2 ; 87$ & 217.23 & $<0.0001$ \\
Hybrid & $1 ; 44$ & 23.52 & $<0.0001$ \\
Date*Mesh & $14 ; 98$ & 13.45 & $<0.0001$ \\
Date*Hybrid & $7 ; 98$ & 0.84 & 0.5541 \\
Mesh*Hybrid & $2 ; 98$ & 0.84 & 0.6907 \\
Large mesh & & & \\
Date & $7 ; 44$ & 58.96 & $<0.0001$ \\
Hybrid & $1 ; 44$ & 3.37 & 0.0733 \\
Date*Hybrid & $7 ; 44$ & 0.48 & 0.8427 \\
Medium mesh & & & \\
Date & $7 ; 43$ & 100.66 & $<0.0001$ \\
Hybrid & $1 ; 40$ & 9.36 & 0.0039 \\
Date*Hybrid & $7 ; 40$ & 1.18 & 0.3355 \\
Small mesh & & & \\
Date & $7 ; 44$ & 31.20 & $<0.0001$ \\
Hybrid & $1 ; 44$ & 19.74 & $<0.0001$ \\
Date*Hybrid & $7 ; 44$ & 3.23 & 0.0075 \\
\hline
\end{tabular}

but not in larger mesh bags, to which all soil animals had access (see below).

Large mesh size There was a significant date effect, but no hybrid effect. Both hybrids decomposed similarly

a

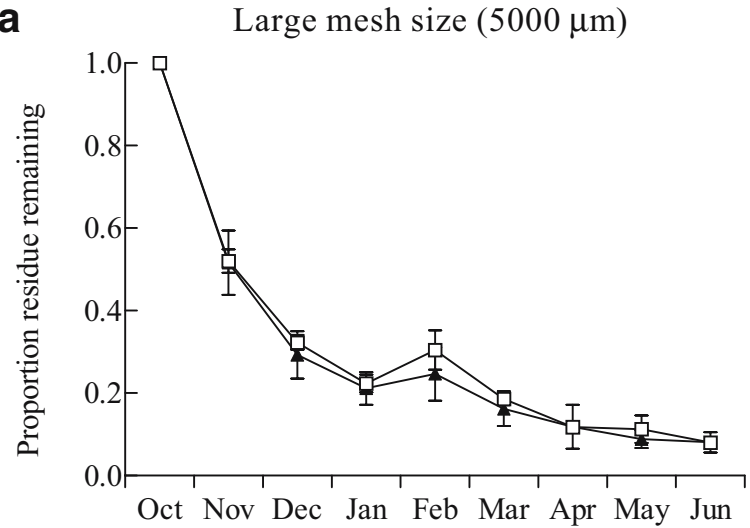

b
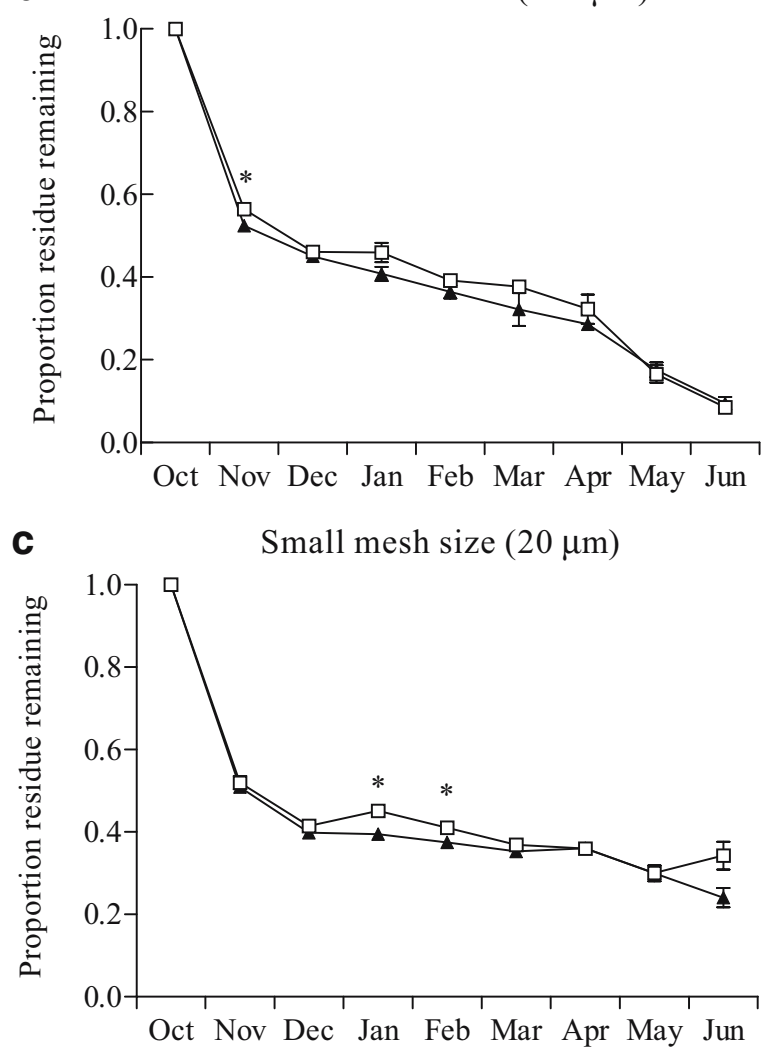

Fig. 3 a-c Mean proportion $( \pm \mathrm{SE})$ of $\mathrm{Bt}$ and non-Bt maize residue remaining (black triangles $\mathrm{Bt}$; white rectangles non- $\mathrm{Bt}$ ) within litterbags with a large $(5,000 \mu \mathrm{m})$, b medium, and $(125 \mu \mathrm{m})$ c small mesh size $(20 \mu \mathrm{m})$. Asterisks represent statistically significant differences at $P=0.05$ 
over time (Table 3). When dates were analyzed separately for a hybrid effect, there were no differences found between the proportion of residue remaining in $\mathrm{Bt}$ and non-Bt maize litterbags (Fig. 3a).

Medium mesh size There were significant date and hybrid effects (Table 3). Bt maize decomposed significantly faster than non-Bt maize (LSMEANS: TukeyKramer-adjusted $P=0.0039$; Fig. 3b). When dates were analyzed separately, there was less Bt maize left than non-Bt maize in November $(d f=1,3 ; F=10.57 ; P=$ 0.0474), but after that, the decomposition of these two hybrids was similar (Fig. 3b).

Small mesh size bags There were significant date, hybrid and date*hybrid interaction effects (Table 3). When dates were analyzed separately, there was significantly less Bt maize than non-Bt maize remaining in January $(d f=1,6 ; F=9.91 ; P=0.0198)$ and February $(d f=1,6 ; F=7.12 ; P=0.0371)$, but not on any of the other dates (Fig. 3c).

Mesh size effects When dates were analyzed separately for each sample date, with the exception of November, there were significant mesh size effects from December thru June (Dec: $d f=2,30 ; F=54.96$; $P<0.0001$; Jan: $d f=2,30 ; F=11.35 ; P<0.0001$; Feb: $d f=2,30 ; \quad F=13.91 ; P<0.0001 ;$ Mar: $d f=2,25 ; \quad F=$ 52.94; $P<0.0001 ;$ Apr: $d f=2,25 ; \quad F=117.68 ; \quad P<$ 0.0001; May: $d f=2,23 ; F=51.90 ; P<0.0001$; Jun: $d f=2,25 ; F=74.24 ; P<0.0001$; Fig. 4). From Decem-

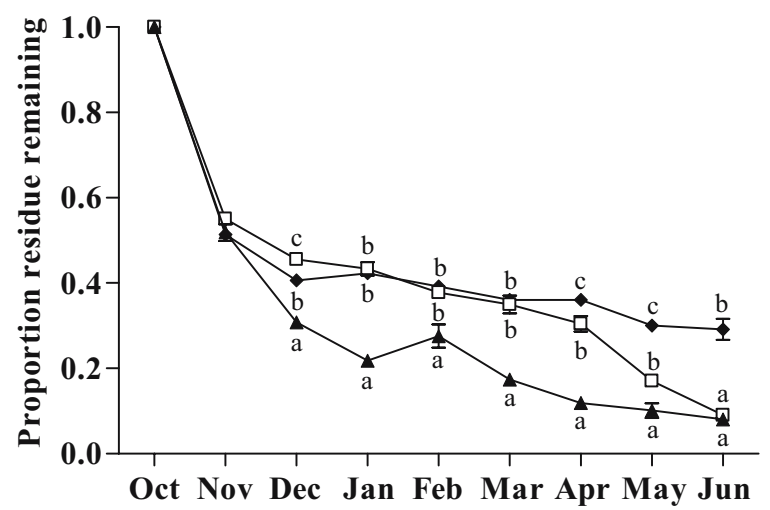

Fig. 4 Comparison of proportion maize residue remaining $( \pm \mathrm{SE})$ in large (black triangles), $(5,000 \mu \mathrm{m})$ medium (white rectangles; $125 \mu \mathrm{m}$ ), and small (black diamonds; $20 \mu \mathrm{m})$ mesh size bags. Different letters represent statistically significant differences at $P=0.005$ at the same sample date. Differences in November were not statistically significant ber through May, the amount of residue remaining was always significantly lower in large than in medium and small mesh bags. In June, the amount of residue remaining in large mesh bags was still lower than in small mesh bags but not than in the medium mesh bags. In December, there was significantly more maize residue left in the medium mesh bags than in small mesh bags. During the following three winter months, from January through March, there were no significant differences in residue remaining between the medium and small mesh size. After that, there was always a significantly smaller amount of residue remaining in medium than in small mesh bags.

\section{Discussion}

Our field study showed a similar decomposition of $\mathrm{Bt}$ and non-Bt residues in large mesh bags. Experiments with large mesh bags represent most accurately what happens in a natural field situation as they allow the whole soil invertebrate community to enter the litterbags and interact with each other. Our results are also in agreement with Lachnicht et al. (2004) who found that $\mathrm{Bt}$ and non-Bt cotton decomposed similarly in the field. In contrast, we found that $\mathrm{Bt}$ maize decomposed faster than non-Bt maize in medium mesh bags, although when comparing single dates this was significant only for November. Similarly, in small mesh bags we found a significantly faster decomposition of Bt than non-Bt maize in January and February. At the end of the experiment, however, the amount of residue left was similar for Bt and non$\mathrm{Bt}$ in all mesh types. Thus, differences in decomposition were rather subtle and not consistent over time.

Possible explanations for the temporal differences in the decomposition of $\mathrm{Bt}$ and non-Bt maize could be attributed to unanticipated changes in the plant compounds, the effects of the Bt protein and/or its metabolites, or both. Unanticipated changes could affect litter quality and, hence, residue decomposition (Raubuch et al. 2007). For instance, the rate of decomposition is often inversely related to the $\mathrm{C}: \mathrm{N}$ and lignin:N ratios (Melillo et al. 1982; Taylor et al. 1989; Heal et al. 1997; Poerschmann et al. 2005). Flores et al. (2005) found a slower decomposition (measured as $\mathrm{CO}_{2}$ evolution) of $\mathrm{Bt}$ maize relative to non-Bt maize in their laboratory study and suggested 
that this might have been due to the higher relative lignin content found in all of their Bt hybrids tested versus the non-Bt maize hybrids tested (Saxena and Stotzky 2001c). These experiments (Saxena and Stotzky 2001c; Flores et al. 2005) included the same two Bt hybrids as used in this experiment. Since we did not measure lignin contents in our samples, we do not know whether they differed from the ones measured by Saxena and Stotzky (2001c). This consistent trend of higher lignin contents in Bt versus non-Bt maize hybrids was found in several, but not all, studies (Masoero et al. 1999; Jung and Scheaffer 2004; Mungai et al. 2005; Poerschmann et al. 2005). Interestingly, Wandeler et al. (2002), who analyzed senescent maize of the same hybrids we used, which were even grown in the same climate chamber as the ones used in this experiment, did not find any significant differences between the nitrogen content of Bt and non-Bt maize. Similar results were found in a recent study where the $\mathrm{C}: \mathrm{N}$ and nitrogen content of 9 week old plants of the same hybrids as used in our experiment were also not significantly different (Griffiths et al. 2007).

Several authors suggest that if some microbial communities have the potential to degrade the $\mathrm{Cry} 1 \mathrm{Ab}$, this extra protein in the environment might cause their proliferation, leading to a faster decomposition of Bt versus non-Bt maize (Blackwood and Buyer 2004; Baumgarte and Tebbe 2005). In this study, there were instances where decomposition of $\mathrm{Bt}$ maize was significantly faster in the small mesh bags, which were only accessible to microorganisms and soil microfauna. On these dates, approximately $20 \%$ of the CrylAb was still present in the plant matrix (results published in Zwahlen et al. 2003a). If the amount of protein in the $\mathrm{Bt}$ residue is higher due to the presence of Cry1 $\mathrm{Ab}$, a concomitant increase in microbial populations on $\mathrm{Bt}$ residue might explain the temporarily faster decomposition of Bt maize found in this study. However, such a positive effect has not been found in several studies that have investigated the effects of Cry1 Ab plants or purified Cry1 $\mathrm{Ab}$ on microorganisms, (Donegan et al. 1995; Saxena and Stotzky 2001a; Blackwood and Buyer 2004; Baumgarte and Tebbe 2005; Griffiths et al. 2005). In contrast, results of Raubuch et al. (2007) on the microbial properties of soil amended with a Bt maize hybrid expressing relatively high levels of Cryl $\mathrm{Ab}$ indicated a significantly reduced microbial communi- ty compared to its control. This hybrid, which had the highest initial $\mathrm{C}: \mathrm{N}$ ratio and Crylab concentration compared to the other hybrids tested, also showed the slowest overall decomposition measured as $\mathrm{CO}_{2}$ evolution. Even if Cry $1 \mathrm{Ab}$ was capable of causing the proliferation of microbial decomposers in their study, it seems other properties had a stronger influence on decomposition than the Cry1 Ab concentration.

Since decomposition of $\mathrm{Bt}$ maize in small and medium mesh bags was at least temporarily significantly faster than of non-Bt maize, one would have expected the same effect in large mesh bags. However, this was not the case. One explanation may be that variance increased with increasing mesh size making it difficult to detect differences between the decomposition of $\mathrm{Bt}$ and non-Bt maize residues in large mesh bags. Another possible explanation for this may lie in our result showing that some macro- and mesofauna were found in lower numbers in Bt residue than non-Bt residue. If this decrease resulted in a lower contribution to overall decomposition, it might account for the net similarity of decomposition in large mesh bags. For instance, significantly less Enchytraeidae were extracted from $\mathrm{Bt}$ than non-Bt residue. Enchytraeidae have been found to account for a high biomass in agricultural soils (de Ruiter et al. 1995) and are known to positively influence decomposition processes and soil structure (Didden 1993; Laakso and Setälä 1999). Since their biomass is rather large compared to the other microinvertebrates that were extracted in high numbers in this study it is conceivable that the Enchytraeidae might have contributed to such an effect.

Besides the Enchytraeidae, the Tullbergiidae and Gamasina also showed higher overall numbers in non-Bt maize than Bt maize, while several related taxa, such as oribatid mites, isotomid and entomobryid collembolans showed similar numbers in both maize hybrids. In total, when analyzing individual dates for each taxon, differences between the Bt and non-Bt treatment were significant in four cases. In three of these cases, there were less individuals (Tullbergiidae and Enchytraeidae) in Bt than non-Bt litterbags. These three cases all occurred when $\mathrm{Cry} 1 \mathrm{Ab}$ protein concentration was still between 0.9 and $3 \mu \mathrm{g} / \mathrm{g}$ Bt maize dry weight (Zwahlen et al. 2003a), thus exposure of soil organisms to Cryl Ab was possible. At the end of the experiment, when little $\mathrm{Cry} 1 \mathrm{Ab}$ was left and the amount of $\mathrm{Bt}$ residue 
left was low, the number of individuals extracted was not significantly different between $\mathrm{Bt}$ and non-Bt residues in any of the taxa investigated.

Whether such relatively subtle effects might lead to significant changes in the soil food web needs further investigation, particularly if $\mathrm{Bt}$ crops are grown repeatedly on a large scale, as is true for large parts of the US Corn Belt. Most studies to date on the effects of purified or transgenic Cry1 Ab expressed in cotton or maize on mites (Oribatida: Oppia nitens Koch) or collembolans, such as Isotomidae (Folsomia candida Willem), Hypogasturidae (Xenylla grisea Axelson), and Onychiuridae (Protaphorura armata Tullberg), addressed the acute hazard of Bt crops. Most of these studies did not find any negative effects on the organisms studied (Sims and Martin 1997, Yu et al. 1997, Clark and Coats 2006; Heckmann et al. 2006), although one study showed a lower survival of $F$. candida when fed with high concentrations of Cry1Ab-containing lyophilized $\mathrm{Bt}$ maize tissue (US Environmental Protection Agency 2001). A long-term field study on the abundance of collembolans in $\mathrm{Bt}$ maize expressing the Cry $3 \mathrm{Bb} 1$ indicated no effect of this Bt maize on collembolan diversity (Bitzer et al. 2005). In our long-term study, individuals of the same taxa as tested in the acute toxicity tests previously mentioned (Oribatida and Isotomidae) did not show any Bt effect. To our knowledge, no study has yet investigated the impact of CrylAb $\mathrm{Bt}$ maize on species of taxonomic groups that were extracted in lower numbers in $\mathrm{Bt}$ than non-Bt maize residue in our experiment. Further studies with these species of these taxa will be necessary to draw any further conclusions.

The question how macro- and mesofauna contribute to the decomposition of plant residue has been addressed in many publications, and it has been suggested that their influence on decomposition is mostly indirect (e.g., Hendrix et al. 1986; VreekenBuijs and Brussaard 1996; Hedlund and Öhrn 2000; Bradford et al. 2002). Although litterbag techniques have been used to find an answer to this question, it has also been criticized due to many reasons thoroughly discussed elsewhere (Bradford et al. 2002). In our experiment, we found that significantly less maize residue was left in litterbags with a larger mesh size than the smallest mesh size, possibly indicating that the meso- and macrofauna substantially contributed to the decomposition process. Although comparisons between small and the two larger mesh bags used in our study are constrained by the facts that small mesh bags were buried in a different depth and contained less residue than the two larger mesh size bags, research by Bradford et al. (2002) showed that increasing the mesh size had a positive effect on decomposition even after accounting for mesh size effects.

Our study investigated whether Bt maize residue itself can directly affect residue decomposition processes. We have found that $\mathrm{Bt}$ maize residues temporarily decomposed faster than non-Bt maize when the majority of soil macroorganisms were excluded, but when the whole soil organism community was allowed to access the residues and interact with each other, the decomposition of $\mathrm{Bt}$ and non-Bt residue was similar. Since the meso- and macrofauna seem to substantially contribute to the decomposition process of the residue, it is crucial to include them in studies on the decomposition of transgenic plant residue. Our results also show clearly that it is important to carry out decomposition studies on different levels of the soil organism community to differentiate effects on various soil organism groups. As we show in our study, effects that were found when excluding larger soil invertebrates were masked or nonexistent when the whole soil invertebrate community had access to the residue. Since the effects in medium and small mesh bags were relatively small and did not persist to the end of the experiments, it is likely that the ecological significance of these effects is of minor importance.

Acknowledgements We would like to thank R. Howald (University of Bern, Switzerland) and K. Barmettler (ETH Zurich, Switzerland) for technical assistance and K. Jost for providing the field. We are grateful to D.A. Andow (University of Minnesota, USA), R. Liesch, H.-R. Roth (ETH Zurich), J.-P. Airoldi, and H. Wandeler (University of Bern), J. Zimmerman (University of Minnesota), S. Kenyon (University of Neuchâtel) and two anonymous reviewers for helpful discussions, advice in statistics, and comments on earlier versions of this manuscript. Many thanks to J. Zettel (University of Bern) for help in the identification of the soil organisms.

\section{References}

Addison JA (1993) Persistence and nontarget effects of Bacillus thuringiensis in soil: a review. Can J For Res 23:23292342

Andow DA, Zwahlen C (2006) Assessing environmental risks of transgenic plants. Ecol Lett 9:196-214 
Atlavinyté O, Galvelis A, Dačiulyté J, Lugauskas A (1982) Effects of entobacterin on earthworm activity. Pedobiologia 23:372-379

Baumgarte S, Tebbe C (2005) Field studies on the environmental fate of the Cry1 Ab Bt-toxin produced by transgenic maize (MON810) and its effect on eubacterial communities in the maize rhizosphere. Mol Ecol 14:2539-2551

Bitzer RJ, Rice ME, Pilcher CD, Pilcher CL, Frankie Lam WK (2005) Biodiversity and community structure of epedaphic and euedaphic springtails (Collembola) in transgenic rootworm Bt corn. Environ Entomol 34:1346-1376

Blackwood CB, Buyer JS (2004) Soil microbial communities associated with $\mathrm{Bt}$ and non-Bt corn in three soils. J Environ Qual 33:832-836

Bottjer KP, Bone LW, Gill SS (1985) Nematoda: Susceptibility of the egg to Bacillus thuringiensis toxins. Exp Parasitol 60:239-244

Bradford MA, Tordoff GM, Eggers T, Jones TH, Newington JE (2002) Microbiota, fauna, and mesh size interactions in litter decomposition. Oikos 99:317-323

Castaldini M, Turrini A, Sbrana C, Benedetti A, Marchionni M, Mocali S, Fabiani A, Landi S, Santomassimo F, Pietrangeli B, Nuti MP, Miclaus N, Giovannetti M (2005) Impact of Bt corn on rhizospheric and soil eubacterial communities and on beneficial mycorrhizal symbiosis in experimental microcosms. Appl Environ Microbiol 71:6719-6729

Chapman M, Hoy MA (1991) Relative toxicity of Bacillus thuringiensis var. tenebrionis on the two-spotted spider mite (Tetranychus urticae Koch) and its predator Metaseiulus occidentalis (Nesbitt) (Acari, Tetranychidae and Phytoseiidae). J Appl Entomol 111:147-154

Clark BW, Coats JR (2006) Subacute effects of transgenic Cry1 Ab $B t$ corn litter on the earthworm Eisenia fetida and the springtail Folsomia candida. Environ Entomol 35:1121-1129

Clark BW, Prihoda KR, Coats JR (2006) Subacute effects of transgenic Cry1Ab Bacillus thuringiensis corn litter on the isopods Trachelipus rathkii and Armadillidium nasatum. Environ Toxicol Chem 25:2653-2661

DeLucca AJ, Simonson JG, Larson AD (1981) Bacillus thuringiensis distribution in soils of the United States. Can J Microbiol 28:452-456

De Ruiter PC, Neutel AM, Moore JC (1995) Energetics, patterns of interaction strengths, and stability in real ecosystems. Science 269:1257-1260

Didden WAM (1993) Ecology of terrestrial Enchytraeidae. Pedobiologia 37:2-29

Donegan KK, Palm CJ, Fieland VJ, Porteous LA, Ganio LM, Schaller DL, Bucao LQ, Seidler RJ (1995) Changes in levels, species and DNA fingerprints of soil microorganisms associated with cotton expressing the Bacillus thuringiensis var. kurstaki endotoxin. Appl Soil Ecol 2:111-124

Escher N, Käch B, Nentwig W (2000) Decomposition of transgenic Bacillus thuringiensis maize by microorganisms and woodlice Porcellio scaber. Basic Appl Ecol 1:161-169

Fearing PL, Brown D, Vlachos D, Meghji M, Privalle L (1997) Quantitative analysis of Cry1A(b) expression in $B t$ maize plants, tissues, and silage and stability of expression over successive generations. Mol Breed 3:169-176

Fierer N, Craine JM, McLauchlan K, Schimel JP (2005) Litter quality and the temperature sensitivity of decomposition. Ecology 86:320-326
Flores S, Saxena D, Stotzky G (2005) Transgenic Bt plants decompose less in soil than non- $B t$ plants. Soil Biol Biochem 37:1073-1082

Gisi U, Schenker R, Schulin R, Stadelmann FX, Sticher H (1997) Bodenökologie. Thieme, Stuttgart, p 350

Griffiths BS, Caul S, Thompson J, Birch ANE, Scrimgeour C, Andersen MN, Cortet J, Messéan A, Sausse C, Lacroix B, Krogh PH (2005) A comparison of soil microbial community structure, protozoa and nematodes in field plots of conventional and genetically modified maize expressing the Bacillus thuringiensis Cry1Ab toxin. Plant Soil 275:135-146

Griffiths BS, Heckmann LH, Caul S, Thompson J, Scrimgeour C, Krogh PH (2007) Varietal effects of eight paired lines of transgenic Bt maize and near-isogenic non-Bt maize on soil microbial and nematode community structure. Plant Biotechnol J 5:60-68

Heal OW, Anderson JM, Swift MJ (1997) Plant litter quality and decomposition: an historical overview. In: Cadisch G, Giller KE (eds) Driven by nature: plant litter quality and decomposition. CAB International, Wallingford, pp 3-29

Heckmann LH, Griffiths BS, Caul S, Thompson J, PusztaiCarey M, Moar WJ, Andersen MN, Krogh PH (2006) Consequences for Protaphorura armata (Collembola: Onychiuridae) following exposure to genetically modified Bacillus thuringiensis (Bt) maize and non-Bt maize. Environ Pollut 142:212-216

Hedlund K, Öhrn MS (2000) Tritrophic interactions in a soil community enhance decomposition rates. Oikos 88:585-591

Hendrix PF, Parmelee RW, Crossley DA, Coleman DC, Odum EP, Groffman PM (1986) Detritus food webs in conventional and no-tillage agroecosystems. BioScience 36:374-380

Hopkins DW, Gregorich EG (2003) Detection and decay of the $B t$ endotoxin in soil from a field trial with genetically modified maize. Eur J Soil Sci 54:793-800

House GJ, Stinner RE (1987) Decomposition of plant residues in no-tillage agroecosystems: Influence of litterbag mesh size and soil arthropods. Pedobiologia 30:351-360

James RR, Difazio SP, Brunner AM, Strauss SH (1998) Environmental effects of genetically engineered woody biomass crops. Biomass Bioenergy 14:403-414

Jung HG, Scheaffer CC (2004) Influence of Bt transgenes on cell wall lignification and digestibility of maize stover for silage. Crop Sci 44:1781-1789

Koehler HH (1999) Predatory mites (Gamasina, Mesostigmata). Agric Ecosyst Environ 74:395-410

Laakso J, Setälä H (1999) Sensitivity of primary production to changes in the architecture of belowground food webs. Oikos 87:57-64

Lachnicht SL, Hendrix PF, Potter RL, Coleman DC, Crossley Jr D (2004) Winter decomposition of transgenic cotton residue in conventional-till and no-till systems. Appl Soil Ecol 27:135-142

MacFadyen A (1961) Improved funnel-type extractors for soil arthropods. J Anim Ecol 30:171-184

MacFadyen A (1962) Soil arthropod sampling. Adv Ecol Res $1: 1-34$

Martin PAW, Travers S (1989) Worldwide abundance and distribution of Bacillus thuringiensis isolates. Appl Environ Microbiol 55:2437-2442

Masoero F, Moschini M, Rossi F, Prantini A, Pietri A (1999) Nutritive value, mycotoxin contamination and in-vitro rumen 
fermentation of normal and genetically modified corn (Cry1Ab) grown in northern Italy. Maydica 44:205-209

Meadows J, Gill SS, Bone LW (1990) Bacillus thuringiensis strains affect population growth of the free-living nematode Turbatrix aceti. Invertebr Reprod Dev 17:73-76

Meissle M, Vojtech E, Poppy GM (2005) Effects of Bt maizefed prey on the generalist predator Poecilus cupreus L. (Coleoptera: Carabidae). Transgenic Res 14:123-132

Melillo JM, Aber JD, Muratore JF (1982) Nitrogen and lignin control of hardwood leaf litter decomposition dynamics. Ecology 63:621-626

Moore JC, Walter DE, Hunt HW (1988) Arthropod regulation of microbiota and mesobiota in belowground detrital food webs. Annu Rev Entomol 33:419-439

Mungai NW, Motavalli PP, Nelson KA, Kremer RJ (2005) Differences in yields, residue composition and $\mathrm{N}$ mineralization dynamics of $\mathrm{Bt}$ and non-Bt maize. Nutr Cycl Agroecosyst 71:101-109

Oatman ER (1965) The effect of Bacillus thuringiensis on some lepidopterous larval pests, apple aphid and predators, and on phytophagous and predaceous mites on young apple trees. J Econ Entomol 58:1144-1147

Ohba M, Aizawa K (1986) Distribution of Bacillus thuringiensis in soils of Japan. J Invertebr Pathol 47:277-282

Poerschmann J, Gathmann A, Augustin J, Langer U, Górecki T (2005) Molecular composition of leaves and stems of genetically modified $\mathrm{Bt}$ and near-isogenic non-Bt maize characterization of lignin patterns. J Environ Qual 34:1508-1518

Raubuch M, Roose K, Warnstorff K, Wichern F, Joergensen RG (2007) Respiration pattern and microbial use of fieldgrown transgenic $B t$ maize residues. Soil Biol Biochem 39:2380-2389

SAS Institute Inc (2004) SAS/STAT ${ }^{\circledR}$ 9.1. SAS Institute Inc., Cary, NC

SAS Institute Inc (2006) The GLIMMIX procedure. SAS Institute Inc. Available from: http://www.sas.com/apps/ demosdownload/setupcat.jsp?cat=SAS\%2FSTAT +Software

Saxena D, Stotzky G (2000) Insecticidal toxin from Bacillus thuringiensis is released from roots of transgenic $B t$ corn in vitro and in situ. FEMS Microbiol Ecol 33:35-39

Saxena D, Stotzky G (2001a) Bacillus thuringiensis (Bt) toxin released from root exudates and biomass of $\mathrm{Bt}$ corn has no apparent effect on earthworms, nematodes, protozoa, bacteria, and fungi in soil. Soil Biol Biochem 33:12251230

Saxena D, Stotzky G (2001b) Bt toxin uptake from soil by plants. Nat Biotechnol 19:199

Saxena D, Stotzky G (2001c) Bt corn has a higher lignin content than non- $B t$ corn. Am J Bot 88:1704-1706

Saxena D, Stotzky G (2003) Fate and effects in soil of insecticidal toxins from Bacillus thuringiensis in transgenic plants. In Collection of biosafety reviews, vol. 1. International Centre for Genetic Engineering and Biotechnology, Trieste, pp 7-83

Saxena D, Flores S, Stotzky G (1999) Insecticidal toxin in root exudates from Bt corn. Nature 402:480

Saxena D, Flores S, Stotzky G (2002) Vertical movement in soil of insecticidal Cry1 Ab protein from Bacillus thuringiensis. Soil Biol Biochem 34:111-120
Scheffer F, Schachtschabel P (1989) Lehrbuch der Bodenkunde. Enke, Stuttgart, p 491

Sims SR, Martin JW (1997) Effect of the Bacillus thuringiensis insecticidal proteins CryIA(b), CryIIA, and CryIIIA on Folsomia candida and Xenylla grisea (Insecta: Collembola). Pedobiologia 41:412-416

Smirnoff WA, Heimpel AM (1961) Notes on the pathogenicity of Bacillus thuringiensis var. thuringiensis Berliner for the earthworm, Lumbricus terrestris Linnaeus. J Insect Pathol 3:403-408

Smith RA, Couché GA (1991) The phylloplane as a source of Bacillus thuringiensis variants. Appl Environ Microbiol 57:311-331

Taylor BR, Parkinson D, Parsons WFJ (1989) Nitrogen and lignin content as predictors of litter decay rates: a microcosm test. Ecology 70:97-104

Turlings TCJ, Jeanbourquin PM, Held M, Degen T (2005) Evaluating the induced-odour emission of a $\mathrm{Bt}$ maize and its attractiveness to parasitic wasps. Transgenic Res 14:807-816

US Environmental Protection Agency (US-EPA) (1997) Pesticide fact sheet. Bacillus thuringiensis CryIA(b) deltaendotoxin and the genetic material necessary for its production (plasmid vector pZ01502) in corn. Office of Prevention, Pesticides and Toxic Substances (7501C)

US Environmental Protection Agency (US-EPA) (2001) Biopesticides registration action document - Bacillus thuringiensis plant-incorporated protectants. 16 October 2001. [online] URL: http://www.epa.gov/pesticides/biopesticides/pips/ bt brad.htm

Vercesi ML, Krogh PH, Holmstrup M (2006) Can Bacillus thuringiensis $(\mathrm{Bt})$ corn residues and $B t$-corn plants affect life-history traits in the earthworm Aporrectodea caliginosa? Appl Soil Ecol 32:180-187

Vreeken-Buijs MJ, Brussaard L (1996) Soil mesofauna dynamics, wheat residue decomposition and nitrogen mineralization in buried litterbags. Biol Fert Soils 23:374-381

Wandeler H, Bahylova J, Nentwig W (2002) Consumption of two $B t$ and six non-Bt corn varieties by the woodlouse Porcellio scaber. Basic Appl Ecol 3:357-365

Yu L, Berry RE, Croft BA (1997) Effects of Bacillus thuringiensis toxins in transgenic cotton and potato on Folsomia candida (Collembola: Isotomidae) and Oppia nitens (Acari: Oribatidae). J Econ Entomol 90:113-118

Zettel J (1999) Blick in die Unterwelt. Ein illustrierter Bestimmungsschlüssel zur Bodenfauna. Agrarökologie, Bern, $\mathrm{p} 110$

Zscheischler J, Estler MC, Staudacher W, Gross F, Burgstaller G (1984) Handbuch Mais. Anbau - Verwertung - Fütterung. Verlagsunion Agrar, Frankfurt am Main, p 253

Zwahlen C, Andow DA (2005) Field evidence for the exposure of ground beetles to Cry1 Ab from transgenic corn. Environ Biosafety Res 4:113-117

Zwahlen C, Hilbeck A, Gugerli P, Nentwig W (2003a) Degradation of Cry1 Ab protein within transgenic Bacillus thuringiensis corn tissue in the field. Mol Ecol 12: 765-775

Zwahlen C, Hilbeck A, Howald R, Nentwig W (2003b) Effects of transgenic Bt corn litter on the earthworm Lumbricus terrestris. Mol Ecol 12:1077-1086 